\title{
Audiobook- the Paradigm of the Portuguese Publishing Market
}

\author{
Paulo Pinheiro ${ }^{1}$, Paula Odete Fernandes ${ }^{2}$ and João Paulo Teixeira ${ }^{3}$ \\ ${ }^{1}$ Instituto Politécnico de Bragança (IPB) \\ ${ }^{2}$ Applied Management Research Unit (UNIAG),Instituto Politécnico de Bragança (IPB) \\ Campus de Santa Apolónia ,Bragança, Portugal \\ ${ }^{3}$ Research Centre in Digitalization and Intelligent Robotics (CEDRI), Instituto Politécnico de \\ Bragança and Applied Management Research Unit (UNIAG), Portugal
}

Correspondence should be addressed to: João Paulo Teixeira; joaopt@ipb.pt

Received date: 26 March 2018; Accepted date: 31 July 2018; published date: 25 January 2019

Academic Editor: Frederico Branco

Copyright (C 2019. Paulo Pinheiro, Paula Odete Fernandes and João Paulo Teixeira. Distributed under Creative Commons CC-BY 4.0

\begin{abstract}
Initially, the audiobook was not a product to be marketed, being produced only for libraries, in order to allow access to information for the blind. In 2005, with the appearance of the first specialized audiobook, publishers in Portugal, the audiobooks began to be produced in order to be commercialized. The audiobook market in Portugal is small, having only 2 companies: Boca palavras que alimentam e a Companhia Nacional de Música. The Portuguese companies have very low sales volumes; which do not exceed a hundred thousand euros. The paper presents the business and production models of audiobooks in USA and proposes their adaptation to Portugal. In order to obtain the degree of acceptance of this format among the Portuguese society, two recordings of a book by a renowned Portuguese writer were made. The two records were made according to a set of technical requirements in order to ensure the quality of the audiobook. The two recordings were evaluated through a questionnaire. The results of the questionnaire are presented and analysed. From the analysis of the questionnaire, it seems that the Portuguese market of audiobooks has yet to be explored. It also seems that it worth the effort because Portuguese community is very open to new technologies and easily uses the internet market. Anyhow, it seems that some marketing campaigns are needed in order to change the actual preference of the printed book face to the virtual version.
\end{abstract}

Keywords: Audiobook, Business Model, Recording Process, Questionnaire.

Cite this Article as: Paulo Pinheiro, Paula Odete Fernandes and João Paulo Teixeira (2019)," Audio book: the Paradigm of the Portuguese Publishing Market" Journal of EU Research in Business, Vol. 2019 (2019), Article ID 651279, DOI: 10.5171/2019.651279 


\section{Introduction}

An audiobook is a book that can be heard instead of being read. It is a recording of a text that can contain music or ambient sounds. The audiobook emerged as a means of allowing book access to people which for various reasons, such as transitory or permanent disability, could not read in the traditional format (printed format).

For many years, the audiobook was an instrument used exclusively by the blind who used this technology to gain access to information. Nowadays due to the lack of time, the audiobook is no longer an exclusively format of blinds and started to be appreciated for population in general. Many people access to this format also because it is useful to help people finish more books in less time and improve the experience of 'read' a book.

The audiobook, because it is not a physical product, has monetary advantages over the printed book, as it does not have the inherent cost of manufacturing, stock, packaging and transportation. Besides that, the audiobook allows readers to read in situations where it would not be possible, for example while performing intellectually less demanding tasks and when doing household chores or exercise.

The audiobook is very widespread in English, however in Portuguese, the offer is very limited and almost all in Brazilian Portuguese, the offer being very limited in European Portuguese. The main purpose of this work is to get familiar with the existing supply of audiobooks in European Portuguese, understand the attitude of the Portuguese publishers in relation to this format and know the acceptance of this format by Portuguese readers. It is also intended to study the variants of narration style for each genre of book and which style is preferred by readers. The technical constrains related to the record of an audiobook are also addressed.
In order to understand the potential of this format in the Portuguese market, two audiobooks from a book by a renowned Portuguese writer were recorded. The quality of the two audiobooks was evaluated by a questionnaire. The results obtained in the questionnaire were subjected to a statistical analysis in order to obtain a relationship between the classifications attributed to the quality of the audiobook and the profile of the subject.

\section{International Audiobook Market}

\section{Anglo-Saxon Countries}

In English-speaking countries, especially in the U.S., the audiobook is a format of general knowledge of the population, with numerous companies dedicated to its production and distribution. Among these companies are: Audible, iTunes, Audiobooks.com, Scribd and Hoopla Digital (Cahill \& Moore, 2017).

In 2007, Amazon bought Audible for 300 million \$, making it the largest seller of audiobooks on the internet. Audible offers audiobooks from leading authors such as Stephen King, Thomas Friedman and Jane Austen, and spoken audio content from news and entertainment program sources such as the New York Times, New Yorker, Fresh Air and Charlie Rose. Their audiobooks are already available in several languages, with producers in countries such as Germany, France, United Kingdom, Italy and Japan (Figueira, 2010).

One of the reasons why this format is so popular in the US is the existence of the Audio Publishers Association (APA). APA is a non-profit-trade association that defends the common commercial interests of audiobook publishers. APA estimates that audiobook sales in 2016 totalled more than $\$ 2.1$ billion (American billions), the third consecutive year in which audiobook sales have increased by nearly 20 percent (Richards, 2017). 


\section{European Portuguese and Brazilian Portuguese Supply}

The audiobooks in European Portuguese are reduced, being mostly about historical books, such as: 'Tabacaria' by Álvaro de Campos, 'O Tesouro' by Eça de Queiroz and 'O Sermão de Santo António' by Padre António Vieira. In spite of this, some audiobooks for children begin to appear, such as the 35 Tales of the Brothers Grimm produced by 'Boca palavras que alimentam' (Figueira, 2010).

The Association of the Blind and the Visually Impaired (ACAPO), in partnership with Biblioteca Sonora do Porto, make available to its associates a repository of about 50 audiobooks. The audiobooks are recorded by volunteers under Article 80 of the Copyright and Related Rights Code of Portugal. In this context, audio reproduction of books is only allowed if strictly intended for visually impaired citizens (Costa, 2018).

The Brazilian market is small, but it is in rapid growth, with the appearance of the first companies like the Ubook, Tocalivros and Livro Acústico. Unlike European Portuguese, in Brazilian Portuguese, it is possible to find a greater number of audiobooks, not only about historical books but also about bestsellers.

\section{Portuguese Companies}

In Portugal, the audiobook is a recent product, arriving to the market at the end of 2005. The market is pretty small being composed only by 2 publishers: Boca palavras que alimentam and Companhia Nacional de Música.
While in the American market the companies operate through the Internet, Portuguese publishers are still very dependent on the physical object and the sale in stores. Because of this, publishers need to use intermediaries, which causes cost increases (Figueira, 2010).

Because the audiobook is being a recent product in the Portuguese market, there is no specific legislation. Audiobook publishers are ruled by the same laws as book publishers, but since the audiobook is not considered a cultural product, instead of paying 6\% VAT like books, it pays a VAT of $23 \%$. So as not to pay this high VAT amount, publishers instead of selling only the audiobook, they sell the CD with the book (Figueira, 2010).

\section{Business Model}

\section{Places of Sale}

In the U.S, where e-commerce is heavily used by the population, the audiobook is mostly purchased over the internet.

Large companies such as Audible, Audiobooks.com or iTunes do not sell their audiobooks in physical locations, but only through the internet. The internet has several advantages to these companies, but the most important of all is the reduction of costs in the transaction, which causes prices to be lower for the consumer (Figueira, 2010)

The internet is also a great place for advertising. According to Figure 1, the Internet is one of the sources of information that most contributes to the dissemination of the audiobook (Malczewski, 2012). 


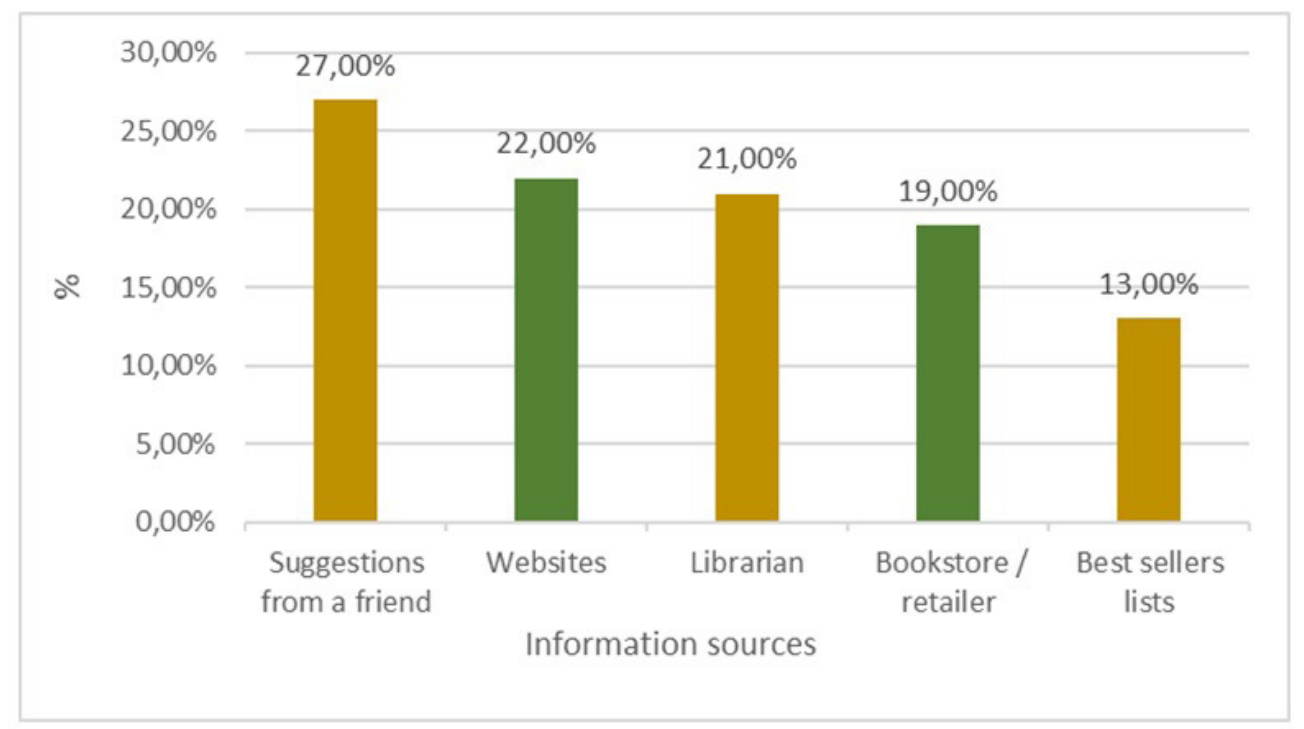

Fig. 1: The most used sources of information for discovering new audiobooks.

Source: produced based on (Malczewski, 2012).

\section{Listening Experience}

The first commercial format for audiobooks was the Vinyl record, this format was overpassed with the introduction of the cassette and CD. Nowadays, the preferred formats of access to the audiobook are the CD and the MP3. Although in recent years the access to the $\mathrm{CD}$ has been decreasing, this format still continues to be greatly appreciated by audiobook enthusiasts, being the preferred format for listening to audiobooks while driving (Richards, 2017).

The table below shows the evolution of consumer preference over the audiobook format.

Table 1 : The most used formats by consumers

\begin{tabular}{|c|c|c|c|c|c|}
\hline & 2011 & 2012 & 2013 & 2014 & 2015 \\
\hline CD & $37,8 \%$ & $34,0 \%$ & $27,8 \%$ & $21,2 \%$ & $15,6 \%$ \\
\hline MP3 download & $58,5 \%$ & $62,9 \%$ & $69,6 \%$ & $76,9 \%$ & $83,1 \%$ \\
\hline Others & $3,5 \%$ & $3,1 \%$ & $2,6 \%$ & $1,9 \%$ & $1,3 \%$ \\
\hline
\end{tabular}

Source: Adapted from Richards (2017).

The information presented in the table is up to the year 2015 , but it is possible to verify the increase in consumption of the download format, this is due to the fact that the download format is cheaper than the physical format because there are no inherent costs of manufacturing, stock, packaging and transportation (Richards, 2017).

On the market, there are several softwares for listening audiobooks, such as Audible and the Audiobooks.com app, which have a wide range of audiobooks. However, these apps do not allow you to play audiobooks that have

Paulo Pinheiro, Paula Odete Fernandes and João Paulo Teixeira (2019), Journal of EU Research in Business, DOI: 10.5171/2019.651279 
been recorded independently; they only play the audiobooks which are present in their bookstores.

The user to play audiobooks by independent record, need to use applications such as: Audiobook Player, Booxio and Audiobooked (Golub et al, 2018). These applications are free and allow the user to divide their work into several chapters; the division of the audiobook into chapters allows the user to know where is in the book and prevents reading to be hard and tedious.

\section{Copyright}

Contrary to what happens in Portugal, the American market is an open market, and there are some forums where authors can contract or exchange ideas with producers. One of the most popular forums is Audiobook Creation Exchange (ACX). ACX is an Audible platform where authors and copyright holders can hire narrators and producers to produce their audiobooks.

At ACX, the Author or the rights owner can choose between two types of contract: exclusivity or non-exclusivity. In the exclusive agreement, if the Author and the Narrator agree to the payment by perfinished-hour rate, the Author gets 40\% royalties on each sale (ACX, 2018).

In the exclusive agreement, if the Author and the Narrator agree to the royalty share deal, $40 \%$ royalties will be divided between the Author who owns the copyright and the Narrator, each receiving $20 \%$ of each sale, while the remaining $60 \%$ of royalties remain with Audible. In the exclusive agreement, the audiobook can only be distributed by the following companies: Audible, Amazon and iTunes.

At non-exclusive agreement, the Author will receive $25 \%$ royalties for each audiobook sold, and their audiobook may be distributed by any company, in this method of payment, the Author must pay to the Narrator directly for the production of the audiobook (ACX,
2018). Regardless of the type of agreement signed, the Author through the \$50 Bounty Program will receive $\$ 50$ each time his audiobook is the first purchase of a new Audible member. In the royalty share deal, the author receives half of the amount and the other part goes to the narrator.

\section{Production Payment}

At the conclusion of the audiobook, the Narrator has the possibility to choose how to get paid, being able to choose one of two different ways: to receive by per-finishedhour rate or by royalty share (ACX, 2018).

By the per-finished-hour rate deal, Narrators are paid according to the total length of the audiobook, in order to help everyone involved, to better estimate the cost of the project. This method is applied because if the copyright owner paid to the Narrator for the total hours spent on the project, he probably would not know how much it would be necessary to spend for the project. On the other hand, the per-finished-hour rate, forces the narrator to be more efficient, since he will receive the same regardless of the time he will spend to carry out the project.

A Narrator approved by Audible, receives on average per hour of recording between 200 to 400 dollars. If the Narrator agrees with the Author, to be paid by per-finished-hour-rate, he will be paid directly by the Author, while in the royalty share deal, the narratoris paid by Audible, receiving $20 \%$ royalties on each audiobook sold and $50 \%$ of the $50 \$$ Bounty program (ACX, 2018).

\section{Narration Styles}

Narration style is an important part of an audiobook success, there is an ideal narration style for each genre of book. If this factor is not taken into account, we may be paying for a narration that does not bring any added value to the audiobook. In a research study by Cahill \& Richey (2015), several styles of narration are mentioned such as: 
Unvoiced, Partially Voiced, Fully Voiced and Full - Cast.

Unvoiced readings are not contrary to what their name might imply; silent, but simple readings of the text with a single voice, without resorting to any kind of representation. Due to its simplicity and being resembling to a simple reading of the book, the Unvoiced narration has a greater potential to failure (Beavin, 1995).

In Partially Voiced readings, the narrator uses distinct voices in the main characters, while in the secondary characters, he keeps the same record without a great emphasis. This form of narration is used in books that revolve around central characters with very characteristic and dominant voices, probably because much of the action is filtered through the sensibility of one of the participants (Beavin, 1995).

The Fully Voiced narration is the most used narration style in the audiobook industry, in which the narrator employs a different voice for each of the characters. This type of narration is appropriate for books in which the characters have very different personalities or traits.

In the Full-Cast narration, several narrators are used to represent different characters; the result is a dramatization of the audiobook which resembles more a movie that is taking place inside our head and less a story to sleep. Although this type of narration may look similar to the Fully Voiced narration, the dynamics of integrating multiple narrators dramatically changes the quality of the audiobook (Mason et al, 2016).

\section{Sound Effects}

As a complement to the narration of the text, many audiobooks contain music and other sound elements. The sound effects present in audiobooks consist mainly of: instrumental music, theme music or page-changing sounds (Cahill \& Richey, 2015).
Music, if used effectively, can represent words, events in history, and reinforce the text. Sound effects like: a door slamming, a piece of paper being kneading and people walking, are all good examples of how to make a good impression, and record in the memory of the listeners the action that is taking place (Cardillo, Coville, Ditlow, Myrick, \& Lesesne, 2007).

\section{Technical Characteristics of Recording}

According to ACX and Author's Republic, to produce high quality audiobooks and maximize sales, it is necessary to respect a set of technical requirements.

The audiobook must be consistent in sound and format, that is, it must be consistent in sound level, tone, noise, spacing and pronunciation allowing the listener a pleasant experience. In order to obtain a good use of the book, an audiobook should have an average spacing of 157 words per minute (Cahill \& Richey, 2015).

The audiobook must be divided into files; each chapter must be an individual file, so the listener can easily navigate between chapters. The audiobook must also contain opening and closing credits, the opening credits must contain the name of the book, author and narrator (ACX, 2018).

Audio files must be free of any external sound such as: microphone pops, mouse clicks, and other sounds that may distract the listener.

Audiobook volume is an important factor, each file should have a volume between $23 \mathrm{~dB}$ to $-18 \mathrm{~dB}$ RMS (Root Mean Square); this range allows listeners not to constantly adjust the volume, allowing the listener to concentrate.

Files should not have peak values greater than $-3 \mathrm{~dB}$, reducing the possibility of distortion, avoiding a reduction in the quality of the audiobook. This value is also essential to ensure that files are successfully encoded. 
The noise is all the sound that should not be part of the recording and distracts the listener. In order not to affect the quality of the audiobook, noise values should not exceed -60 dB RMS.

All files must be recorded in mono with a sampling rate of $44.1 \mathrm{kHz}$, and coded in MP3 or M4A at a Constant Bit Rate (CBR) of 192 kbps.

The Audiobook must be narrated by a human voice. Recordings in Text-to-Speech are not allowed. Listeners choose audiobooks for the performance of their narrators and for the quality of their story. To have this experience, it is essential to be recorded by a human and not by a machine (ACX, 2018).

\section{Recording Experiment}

The recording of a book was performed into two styles in order to experience the difficulties related to this process.

\section{Recording Studio}

The place used in the recording of the audiobook was the recording studio of the faculty (Escola Superior de Educação do Instituto Politécnico de Bragança), because it presents a good insulation to the outside noise and good acoustic conditions for the practice of audio recording. The studio has an acoustic coating on Rockwool.

ACX presents on its website a list of microphones recommended by its recording professionals. Most of the microphones on the list are Large Diaphragm Condenser microphones. (Pinheiro et al., 2018)

These microphones are used in studio recording, because they have a high sensitivity and a lower signal saturation, which makes them ideal for vocal recording (Pinheiro et al., 2018). Another factor for their use in the studio is that these microphones are quiet, which greatly reduces the recording time.
The microphone used was Studio Projects C1. Studio Projects $\mathrm{C} 1$ is an externally polarized cardioid type microphone with a Field Effect Transistor (FET) with an impedance converter. The microphone used was a condenser microphone, so it needs a preamplifier to work (Alten, 2012). The preamplification was done by a $48 \mathrm{~V}$ Phantom Power, which was supplied by the M-Audio DMP2 preamplifier.

The recording software used for recording and editing the audiobook was Audacity, because it is a free and intuitive software which facilitates the editing process. Besides these factors, it is one of the recommended software in the audiobook industry.

\section{The Book and the Narrator}

The chosen book was "A Fada Oriana" by Sophia de Mello Breyner (Breyner, 1964), because it is a book by a well-known Portuguese writer. In addition, this book is part of the study plan of the elementary school in Portugal, which makes it a wellknown book by the majority of the Portuguese population.

The record of the audiobook was made by female narrators, because they are of the same genre as the main characters of the book. Both narrators have experience in studio recording.

The first record was read by only one narrator, having been used in the narration the Partially Voiced style, due to the fact that most of the book's action was filtered by the sensitivity of one of the characters. During the reading of the first record, the narrator used different voices in the main characters, while in the secondary characters used the same vocal record.

The second record was read by two narrators, so the narration style used was Full - Cast. The main character and the story narrator were read by the same person of the first audiobook, while the other characters were narrated by another person. 


\section{Questionnaire and Results}

A survey was conducted using the Google forms platform and was divided into four groups of questions. The first group of questions was designed to profile the subject, asking questions related to the age, gender and qualifications of the subject. With the second group, it was intended to know the opinion of the subjects regarding the format, while the third and fourth group were referring to the sound quality of the recorded audiobooks, with one and two narrators respectively.

A preliminary questionnaire was conducted in order to correct some misunderstood questions. After these corrections the following questions were used.

\section{Questions}

As previously mentioned, the questionnaire was divided into four groups of questions, according to their purpose. In order to characterize the subject, the following questions were asked:

- What is your Gender?

- What age group are you in?

- What is your formation (completed)?

- Indicate the study area of the course you are attending or attended.

- How many books do you read per year?

- How many audiobooks have you heard?

In order to understand the acceptance of the audiobook format among the subjects, the following questions were asked:

- Which of the following formats would you choose to read a book?

- Would you buy an audiobook?

- If you answered yes, please indicate the reason for the purchase.
- What would be the location used to purchase an audiobook?

Concerning the sound quality of the audiobook narrated by one narrator, subjects were asked about the following parameters:

- How appropriate is the Narrator's voice?

- How is the reading pace?

- Which classification do you attribute to the interpretation of different characters?

- What rating do you attribute to the sound quality of the audiobook?

Concerning the sound quality of the audiobook narrated by two narrators, the subjects were asked about the following parameters:

- How appropriate is the voice of the Narrators?

- How is the reading pace?

- Which classification do you attribute to the interpretation of the different characters?

- What rating do you attribute to the sound quality of the audiobook?

At the end of the questionnaire, subjects were asked about their preference between the two types of narration, Partially Voiced or Full-Cast.

The answer options are presented in the analysis of results section.

\section{Results}

In this second questionnaire, it was possible to obtain a sample higher than that obtained in the preliminary questionnaire; obtaining a sample of 68 people/answers. Contrary to what had occurred in the preliminary questionnaire, this questionnaire counted on the answers of subjects who are not part of the student's academy.

The questions related to the characterization of the subjects are analysed below. 
In the cheeses diagram below, the gender of the sample obtained is characterized.
Fig. 2 presents the analysis of the first question. The questionnaire was made in Portuguese language. The female gender is the predominant gender, representing $60.3 \%$ of the total sample.

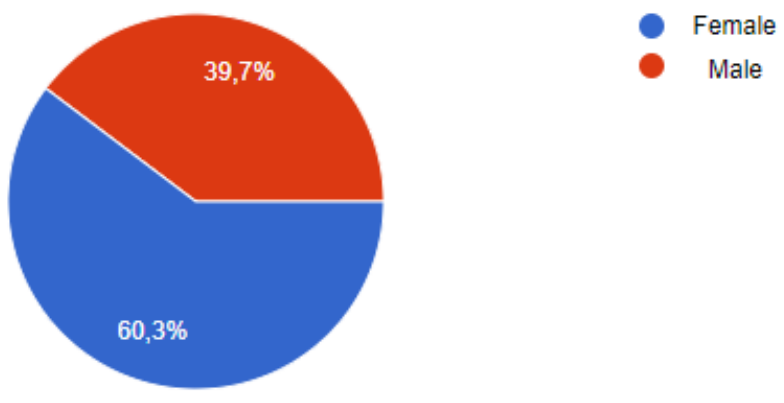

Fig. 2: Gender of the respondents

According to Fig. 3, the vast majority of subjects are in the 19-25 age group and are therefore young adults. Although the majority of the sample was young adults (1925 years), it was possible to collect a diversified sample,

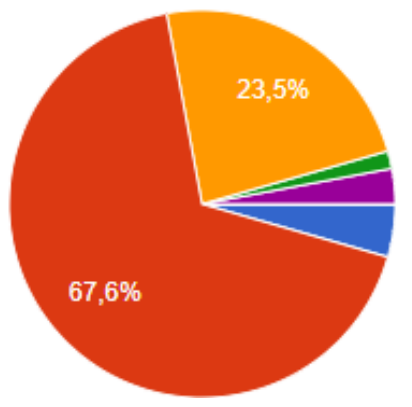

containing subjects less than 18 years of age and aged between 46 and 55 years.

Fig. 3: Age Group of the sample

Regarding the educational level (Fig. 4), the level with the highest percentage of results was the Bachelor's Degree (3-year graduation), with $47.1 \%$ of the answers. 


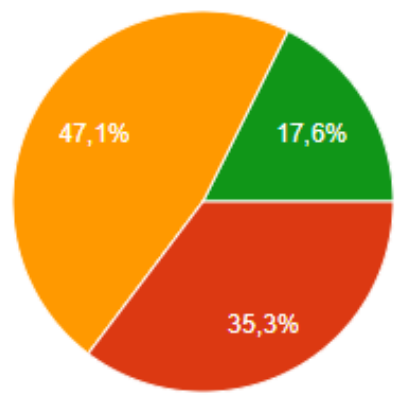

Elementary School

High School

Bachelor's

Master or PhD

Fig. 4: Education Level of the subjects

The second level of education with the highest number of answers was the High School with $35.3 \%$ of the answers, while the Master's or PhD degree was the educational level, with the lowest number of results, with $17.6 \%$ of the answers obtained.

Figure 5 shows the area of study that subjects are attending or attended.

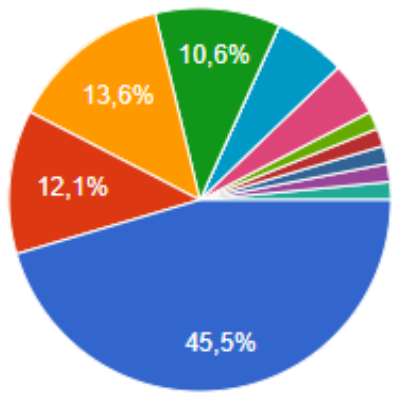

\author{
Engineering \\ Sciences \\ Health \\ Education \\ None \\ Management \\ Tourism \\ Accounting
}

Fig. 5: Study area of the course attending or attended by the subjects

In the questionnaire, subjects from the most diverse areas were obtained, with engineering being the area with the highest representation among the subjects.
In the cheese diagram below (Fig. 6), the number of books read per year by the subjects is displayed. 


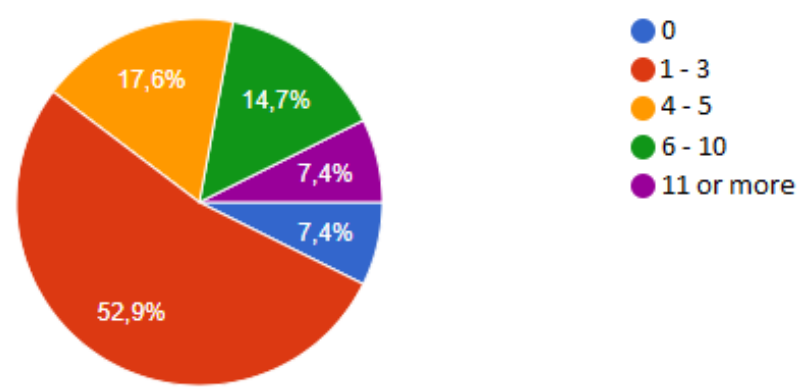

Fig. 6: Number of books read per year

The majority of the subjects have reading habits, usually reading between 1 and 3 books per year. Only $7.4 \%$ of the sample, representing 5 subjects, replied that they did not read any book per year.
In relation to the number of audiobooks listened by the subjects, it is possible to verify through the cheese diagram below (Fig. 7) the lack of knowledge of this format among Portuguese society.

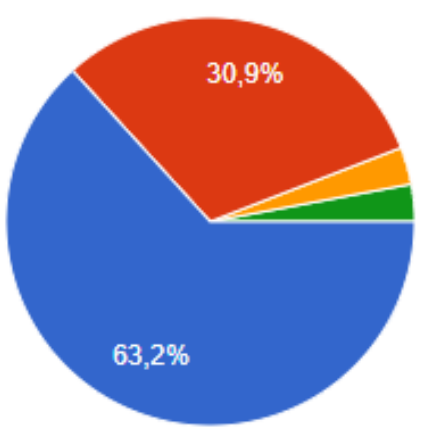

Fig. 7: Number of audiobooks heard by the sample

For the majority of the sample, this was the first time they had contact with an audiobook, with $63.2 \%$ of the subjects who had never heard an audiobook.

The second group of questions concerning acceptance of the audiobook format is analysed below.
Fig. 8 shows the preference of the subjects regarding the format chosen for reading a book.

The format with the largest number of answers was the printed book with $88.2 \%$. The audiobook and the E-book appear in the second position, both with 4 replies each. 


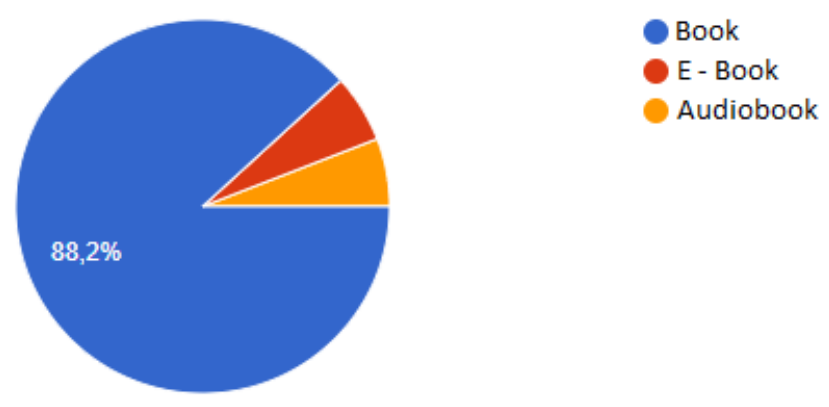

Fig. 8: Chosen format to read a book

In the cheese diagram below (Fig. 9), the subjects' interest in acquiring the spoken version of the book is presented.

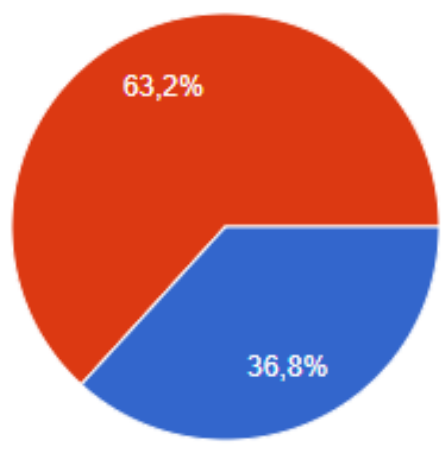

\section{Fig. 9: Subjects' interest in acquiring the spoken version of the book}

The big majority of the sample replied that they would not buy an audiobook, with the No getting $63.2 \%$ of the answers. However, it was still possible to obtain a significant percentage of subjects who responded that they would acquire the spoken version of the book.
These results denote the need to some marketing in order to change the position of the potential audiobook consumers.

Following this question, subjects who answered yes, they were asked to indicate the reason for the purchase of the spoken version of the book. 


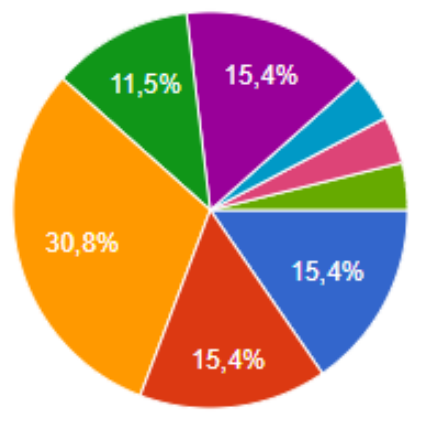

To Study

Read more books

Reading while doing physical exercise or household chores

To Relax

- Learning a new language

- Reading Problems

- For Travel

- Read while doing something else and learn a new language

Fig. 10: Reasons mentioned by the subjects to buy an audiobook

The reason mostly answered by the subjects to the purchase of the spoken version of the book (Fig. 10) was the possibility to read while doing exercise or household chores. However, the subjects pointed out other reasons, such as: reading more books, studying, learning a new language or

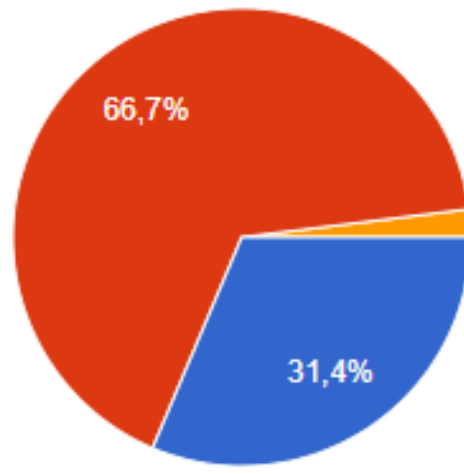

relaxing.

Fig. 11 shows the results concerning the location chosen by the subjects to purchase an audiobook.

Fig .11: The chosen place for the purchase of the spoken version of the book 
The place with the largest number of answers was the Internet, with $66.7 \%$ of the answers, which shows the level of maturity of the e-commerce in Portugal. In the second place, the physical store appears with $31.4 \%$ of the answers.
The third group of questions concerning the sound quality of the audiobook narrated by one narrator is analysed below.

Regarding the quality of the voice of the narrator for the chosen book, it is possible to verify by the cheese diagram of Fig. 12, that the narrator presents a proper voice for the narration of the book.

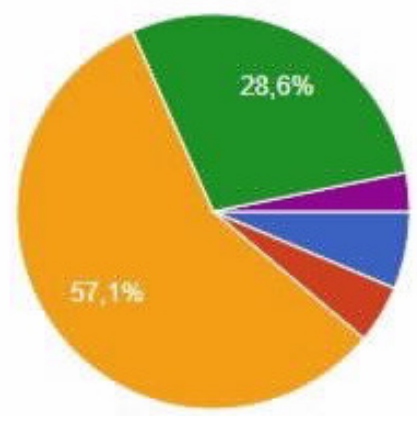

Totally Inappropriate

Little Appropriate

Proper

Very Appropriate

Fully Appropriate

Fig. 12: Quality of the voice of the narrator for the chosen book

The ranking with the highest consensus among the subjects was the Proper, with $57.1 \%$ of the answers, followed by the Very Appropriate, with $28.6 \%$ of the answers.
Fig 13 presents the classification attributed to the reading pace present in the audiobook with one narrator.
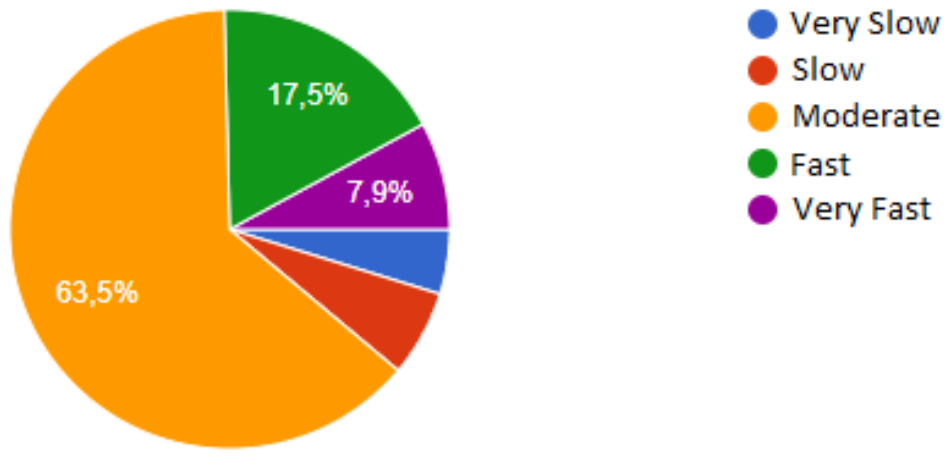

Fig. 13: Reading pace in the audiobook with one narrator 
The ranking with the highest percentage of choices was the Moderate, with $63.5 \%$ of the answers, followed by the Fast with $17.5 \%$ of the answers.

According to the opinion expressed by the subjects, the interpretation given to the different characters in the book was Good, being the classification with the highest percentage of answers, as can be seen in the diagram presented in Fig. 14.
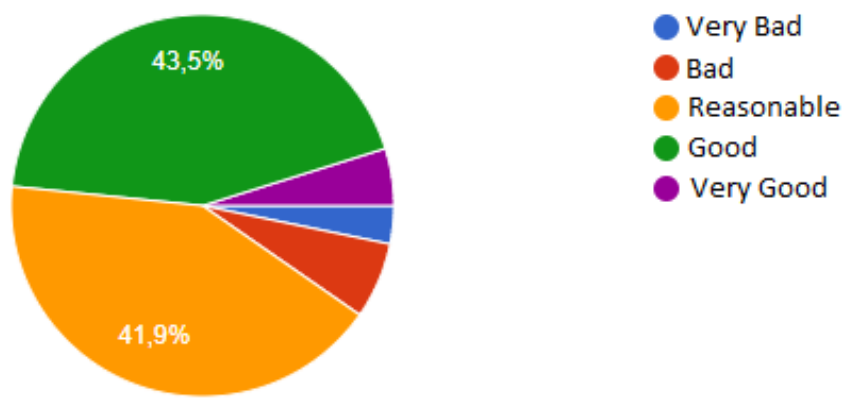

Fig. 14: Classification attributed to the interpretation of the different characters in the audiobook with one narrator

The last question about the audiobook with one narrator is related to the sound quality of the recording. The majority of the subjects considered the sound quality Good, obtaining $50.8 \%$ of the answers (Fig. 15).
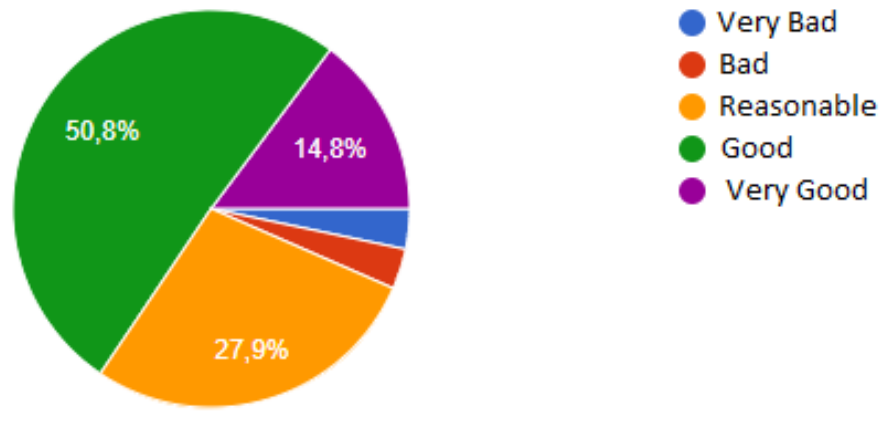

Fig. 15: Sound quality of the audiobook with one narrator

Paulo Pinheiro, Paula Odete Fernandes and João Paulo Teixeira (2019), Journal of EU Research in Business, DOI: 10.5171/2019.651279 
The second most attributed classification was the Reasonable with $27.9 \%$ of the answers, followed by the Very Good with $14.8 \%$ of the answers.

The fourth group of questions concerning the sound quality of the audiobook narrated by two narrators is analysed below.
In the audiobook with two narrators, the subjects considered the voices of the narrators (Fig. 16) Proper for the narration of the chosen book.

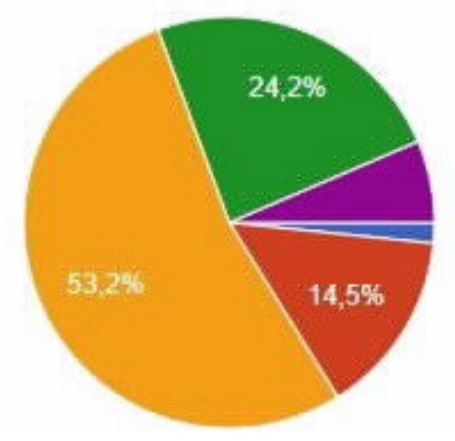

Totally Inappropriate

Little Appropriate

Proper

Very Appropriate

Fully Appropriate

\section{Fig. 16: Quality of the voice of the narrators for the chosen book}

Among the most answered classification, we can find the Very Appropriate with $24.2 \%$ of the answers and, Little Appropriate with $14.5 \%$ of the answers.
According to the vast majority of the subjects, the reading pace (Fig. 17) present in the recording with two narrators was Moderate with $65 \%$ of the answers.

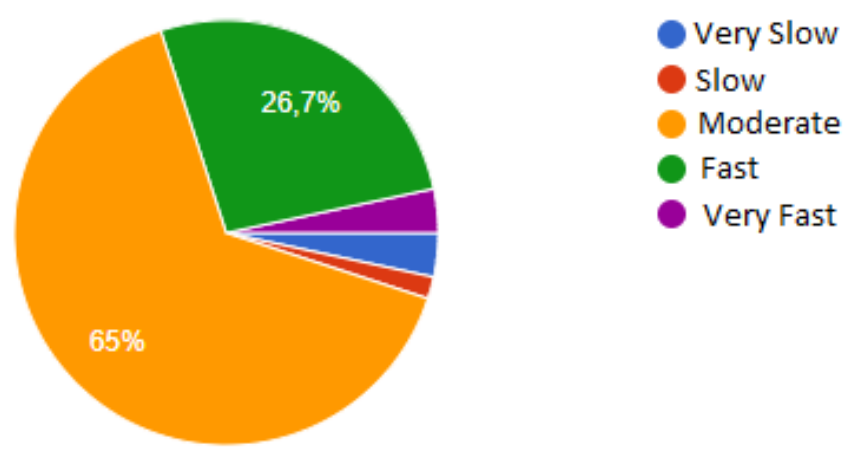

Fig. 17: Reading pace in the audiobook with two narrators

Paulo Pinheiro, Paula Odete Fernandes and João Paulo Teixeira (2019), Journal of EU Research in Business, DOI: 10.5171/2019.651279 
In the second position, we have the Fast with $26.7 \%$ of the answers. Only $8.3 \%$ of the subjects chose a different reading pace than Moderate and Fast.
The interpretation of the different characters (Fig. 18) in the audiobook with two narrators is considered by the subjects as Reasonable, being the most answered classification with $41.9 \%$ of the answers.

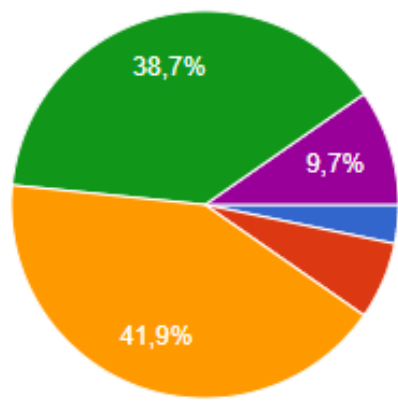

Very Bad

Bad

Reasonable

Good

Very Good

Fig. 18: Classification attributed to the interpretation of the different characters in the audiobook with two narrators

Among the most answered rankings, we have Good with $38.7 \%$ of the answers, followed by Very Good with $9.7 \%$ of the answers. In general, subjects considered the interpretation of the different characters to be satisfactory, with only $9.7 \%$ of the subjects considering the Bad or Very Bad interpretation for the chosen book.

In the recording with two narrators, the classification with the highest consensus among subjects, for the sound quality of the audiobook, was Good with $53.2 \%$ of the answers (Fig. 19).

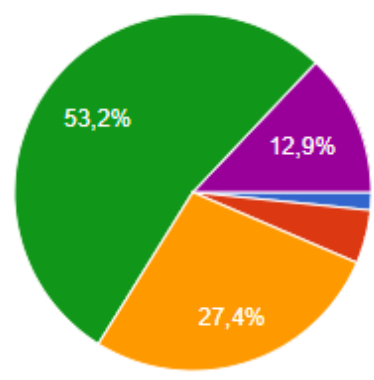

Very Good

Fig. 19: Sound quality present in the audiobook with two narrators

Paulo Pinheiro, Paula Odete Fernandes and João Paulo Teixeira (2019), Journal of EU Research in Business, DOI: 10.5171/2019.651279 
At the end of the questionnaire, subjects were asked about their preference between the two types of narration, Partially Voiced

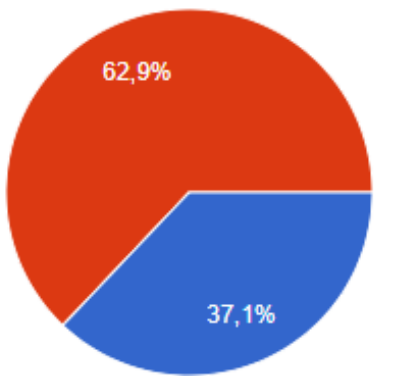

Fig. 20: Style of Narration preferred by the subjects

The narration style with the highest percentage of answers was the Full - Cast, with $62.9 \%$ of the answers.

Although the sample gave preference to the Full-Cast style, the results obtained in relation to the quality of the audiobooks were similar. In both recordings, the narrators presented a proper tone of voice, in a moderate rhythm and with good sonority, as to the role interpreted by the narrators in relation to the different characters, a reasonable result was obtained.

\section{Cross Information Results}

Table 2: Mean and Standard Deviation of the ratings assigned by the subjects on the narrator's voice and the pace of reading, according to the gender, age group and formation

\begin{tabular}{|c|c|c|c|c|c|c|c|c|c|c|}
\hline \multirow{2}{*}{ Variables } & \multicolumn{4}{|c|}{$\begin{array}{c}\text { How appropriate is the voice } \\
\text { of the Narrators? }\end{array}$} & \multicolumn{2}{c|}{ How is the reading pace? } \\
\cline { 2 - 13 } & \multicolumn{3}{|c|}{ Partially Voiced } & Full-Cast & \multicolumn{2}{c|}{$\begin{array}{c}\text { Partially } \\
\text { Voiced }\end{array}$} & \multicolumn{2}{c|}{ Full-Cast } \\
\cline { 2 - 13 } & $\mathbf{n}$ & Mean & Std & Mean & Std & Mean & Std & Mean & Std \\
\hline \multirow{2}{*}{ Gender } & Female & 36 & 3,17 & 0,878 & 3,17 & 0,822 & 3,17 & 0,775 & 3,24 & 0,554 \\
\cline { 2 - 12 } & Male & 27 & 3,19 & 0,786 & 3,22 & 0,847 & 3,19 & 0,962 & 3,26 & 0,859 \\
\hline \multirow{2}{*}{ Age Group } & 18 or less & 3 & 3,50 & 0,707 & 3,50 & 0,707 & 3,00 & 0,000 & 3,00 & 0,000 \\
\cline { 2 - 11 } & $19-25$ & 42 & 3,10 & 0,932 & 3,20 & 0,901 & 3,07 & 0,894 & 3,15 & 0,770 \\
\hline
\end{tabular}

Similar to the statistical analysis carried out in the preliminary questionnaire, the results related to the quality of the recorded audiobooks were grouped according to the gender, age and formation of the subjects. Each of the answers was assigned a weight between 1 and 5 , with 1 being the most unfavourable classification and 5 being the most favourable classification.

Table 2 presents the mean and standard deviation (Std) of the subject's answers to the quality of the narrators' voice and the reading pace, according to the gender, age and formation of the subjects. or Full - Cast. In the diagram of Fig. 20 the preferences of the subjects regarding the type of narration is presented.
Partially Voiced

Full - Cast

Paulo Pinheiro, Paula Odete Fernandes and João Paulo Teixeira (2019), Journal of EU Research in Business, DOI: 10.5171/2019.651279 


\begin{tabular}{|c|c|c|c|c|c|c|c|c|c|c|}
\hline & 26 or more & 19 & 3,32 & 0,582 & 3,16 & 0,688 & 3,42 & 0,769 & 3,47 & 0,513 \\
\hline \multirow{4}{*}{ Formation } & High School & 23 & 3,22 & 0,951 & 3,35 & 0,832 & 3,13 & 0,815 & 3,23 & 0,612 \\
\cline { 2 - 10 } & Bachelor & 29 & 3,14 & 0,875 & 3,14 & 0,803 & 3,24 & 0,912 & 3,25 & 0,844 \\
\cline { 2 - 10 } & $\begin{array}{c}\text { Master or } \\
\text { PhD }\end{array}$ & 11 & 3,18 & 0,405 & 3,00 & 0,894 & 3,09 & 0,831 & 3,27 & 0,467 \\
\hline
\end{tabular}

Through the application of the T - Student test for paired samples, it was possible to verify the absence of statistically significant differences, in order to establish a relationship between gender, age, formation of the subjects and the classifications attributed to the voice quality of the narrators and to the reading pace. However, there are some trends that should be pointed out.

In the questionnaire, the male gender considered the reading pace in the audiobook narrated by two narrators, faster than the female genre.

Regarding the age group of the subjects, it is possible to observe that younger subjects gave better ratings to the voice quality of the narrators' than subjects older than 26 years old, in turn, older subjects considered the reading pace faster than younger subjects.

In both recordings, the subjects without higher education gave better ratings to the quality of the narrators' voice and to the reading pace than the subjects with higher education.

Table 3 presents the mean and standard deviation of the answers given by the subjects to the interpretation of the different characters and to the sound quality of the recordings.

Table 3 : Mean and Standard Deviation of the ratings assigned by the subjects on the interpretation of different characters and to the sound quality, according to the gender, age group and formation

\begin{tabular}{|c|c|c|c|c|c|c|c|c|c|c|}
\hline \multirow{3}{*}{\multicolumn{2}{|c|}{ Variables }} & \multicolumn{5}{|c|}{$\begin{array}{l}\text { Which classification do you } \\
\text { attribute to the interpretation } \\
\text { of the different characters? }\end{array}$} & \multicolumn{4}{|c|}{$\begin{array}{c}\text { What rating do you } \\
\text { attribute to the sound } \\
\text { quality of the audiobook? }\end{array}$} \\
\hline & & \multicolumn{3}{|c|}{ Partially Voiced } & \multicolumn{2}{|c|}{ Full-Cast } & \multicolumn{2}{|c|}{$\begin{array}{c}\text { Partially } \\
\text { Voiced }\end{array}$} & \multicolumn{2}{|c|}{ Full-Cast } \\
\hline & & $\mathbf{n}$ & Mean & Std & Mean & Std & Mean & Std & Mean & Std \\
\hline \multirow{2}{*}{ Gender } & Female & 35 & 3,46 & 0,852 & 3,43 & 0,815 & 3,86 & 0,879 & 3,83 & 0,747 \\
\hline & Male & 27 & 3,33 & 0,784 & 3,48 & 0,975 & 3,50 & 0,860 & 3,56 & 0,892 \\
\hline \multirow{3}{*}{ Age Group } & 18 or less & 3 & 3,50 & 0,707 & 4,00 & 0,000 & 3,50 & 0,707 & 4,00 & 0,000 \\
\hline & $19-25$ & 41 & 3,39 & 0,919 & 3,44 & 1,001 & 3,68 & 0,934 & 3,66 & 0,883 \\
\hline & 26 or more & 19 & 3,42 & 0,607 & 3,42 & 0,607 & 3,78 & 0,808 & 3,79 & 0,713 \\
\hline \multirow{3}{*}{ Formation } & High School & 23 & 3,43 & 0,896 & 3,43 & 0,896 & 3,82 & 0,958 & 3,83 & 0,778 \\
\hline & Bachelor & 28 & 3,36 & 0,870 & 3,50 & 0,839 & 3,64 & 0,870 & 3,61 & 0,832 \\
\hline & Master or PhD & 11 & 3,45 & 0,522 & 3,36 & 1,027 & 3,64 & 0,809 & 3,73 & 0,905 \\
\hline
\end{tabular}

Paulo Pinheiro, Paula Odete Fernandes and João Paulo Teixeira (2019), Journal of EU Research in Business, DOI: 10.5171/2019.651279 
The differences between the means obtained are not significant to establish a relationship between the gender, age, formation of the subjects and the assigned classifications.

Analysing the values of the means, it is possible to state with respect to the gender of the subjects, that the female gender gave better classifications to the interpretation and sound quality of the audiobooks, than the male gender.

Regarding the age group of the subjects, subjects aged 18 years or less considered interpretation and sound quality more appropriate than older subjects.

The means obtained regarding the formation of the subjects indicate that the subjects without higher education considered the sound quality of the audiobook more adequate than the subjects with higher education. Subjects with higher education, on the other hand, attribute better classifications to the interpretation of the different characters than the subjects without higher education.

\section{Conclusions}

In Portugal, the audiobook market is small and with low visibility, with only two companies active. With the purpose of presenting ideas to boost the Portuguese audiobooks market, a research was made about the business and production models present in more developed markets.

With the study done about the American market, it was possible to conclude that for Portuguese companies to achieve success, their number should increase and develop efforts on their virtualization and promote the creation of an association of audiobook publishers.

The tax policy that applies a VAT of $6 \%$ for books and 23\% for Audiobook also penalise this industry. The Portuguese companies adapt to include the audiobook in a CD format with the book. The business model of Audiobooks in Portugal can be improved. This new format will lead to more books being acquired and 'read', in this case heard by the readers, so it will contribute to increase the reading / listening culture of books and should be encouraged by reducing the VAT tax to the minimum value.

In order to understand the potential of this format in the Portuguese market, two audiobooks from a book by a renowned Portuguese writer were recorded. The two audiobooks were subjected to a questionnaire, in order to understand the level of acceptance of this format among the student's academy. The questionnaire results were subjected to a statistical analysis to establish a relationship between the gender, age, literary abilities of the subject and the classifications assigned in the questionnaire. Through the application of the Student's ttest for paired samples, it was possible to verify the absence of statistically significant differences, in order to establish a relationship between the gender, age, literary abilities of the subjects and the classifications assigned in the questionnaire. Despite this, there are some relevant trends, such as the fact that the female gender has given better ratings than the male gender or the fact that the subjects without higher education gave better ratings than those with higher education.

From the analysis of the questionnaire it seems that the Portuguese market of audiobooks has yet to be explored. It also seems that it worth the effort because Portuguese community is very open to new technologies and easily uses the internet market. Anyhow it seems that some marketing campaigns are needed in order to change the actual preference of the printed book face to the virtual version. 
As a future work, it is proposed to extend the questionnaire to larger population covering different groups of the Portuguese society besides the student's academy, and experiment the other types of audio products such as notices.

\section{Acknowledgments}

We are very grateful to Diana Ferreira and Ana Monteiro for their participation as narrators in the various recordings.

This work is supported by the Fundação para a Ciência e Tecnologia (FCT) under the project number UID/GES/4752/2016.

\section{References}

1. ACX. (2018). Weblet Importer. Retrieved March 15, 2018, from https://www.acx.com/help/authors/200484 540

2. Alten, S. R. (2012). Recording and Producing Audio for Media. Course Technology Cengage Learning.

3. Beavin, K. (1995). Audiobooks: Four Styles of Narration. Horn Book Magazine, 72.

4. Breyner, S. M. (1964). A Fada Oriana. Figueirinhas.

5. Cahill, M., \& Moore, J. (2017). A Sound History, Audiobooks are Music to Children's Ears. Children and Libraries.

6. Cahill, M., \& Richey, J. (2015). What Sound
Does an Odyssey Make? Library Quarterly: Information, Comunity, Policy, 85.

7. Cardillo, A., Coville, B., Ditlow, T., Myrick, E., \& Lesesne, T. (2007). Turning in to Audiobooks. Association for Library Service to Children, Children L.

8. Costa, J. (2018). Biblioteca Sonora Digital. Retrieved March 15, 2018, from http://arquivodigital.cm-

porto.pt/Conteudos/Conteudos_BPMP/BDigi tal/Projectos/BSDigital/BSDigital_Perguntas Frequentes.htm

9. Figueira, R. (2010). O novo livro: conteúdo virtual gerador de lucro real?

10.Golub, S., Pilgun, A., \& Galias, I. (2018). Booxio Audiobook Player. Retrieved February 27, 2018, from https://boox.io/

11.Malczewski, B. (2012). Multi-Tasker's Dream. Library Journal.

12.Mason, R., Michael, N., \& Deward, E. (2016). The Audiobook Book: An Audiobook Production Guide for Indie Authors. Mad Mason Press.

13.Pinheiro, P., Fernandes, P. \& Teixeira, J. P. (2018). Audiobooks Business Model Technologic Challenges, Case Study, In Proceedings of 31st International Business Information Management (IBIMA) Conference. Milan. 14.Richards, J. (2017). Audiobooks Continues Double-Digit Growth. Audio Publishers Association (APA). 